\title{
Comparison of the 7th and 8th editions of the American joint committee on cancer TNM classification for patients with stage III gastric cancer
}

\author{
Jun Lu ${ }^{1,2,3,4}$, Chao-Hui Zheng ${ }^{1,2,3,4}$, Long-Long Cao ${ }^{1,2,3,4}$, Ping Li ${ }^{1,2,3,4}$, Jian-Wei Xie ${ }^{1,2,3,4}$, \\ Jia-Bin Wang ${ }^{1,2,3,4}$, Jian-Xian Lin ${ }^{1,2,3,4}$, Qi-Yue Chen ${ }^{1,2,3,4}$, Mi Lin ${ }^{1,2,3,4}$, Ru-Hong Tu, 1,2,3,4 \\ and Chang-Ming Huang ${ }^{1,2,3,4}$ \\ ${ }^{1}$ Department of Gastric Surgery, Fujian Medical University Union Hospital, Fuzhou, China \\ ${ }^{2}$ Department of General Surgery, Fujian Medical University Union Hospital, Fuzhou, China \\ ${ }^{3}$ Key Laboratory of Ministry of Education of Gastrointestinal Cancer, Fujian Medical University, Fuzhou, China \\ ${ }^{4}$ Fujian Key Laboratory of Tumor Microbiology, Fujian Medical University, Fuzhou, China \\ Correspondence to: Chang-Ming Huang, email: hcmlr2002@163.com \\ Keywords: gastric cancer, TNM classification, prognosis, 8th edition \\ Received: February 02, $2017 \quad$ Accepted: April 26, $2017 \quad$ Published: June 06, 2017 \\ Copyright: Lu et al. This is an open-access article distributed under the terms of the Creative Commons Attribution License 3.0 (CC \\ BY 3.0), which permits unrestricted use, distribution, and reproduction in any medium, provided the original author and source are \\ credited.
}

\section{ABSTRACT}

Background and Objectives: The eighth TNM edition for gastric cancer was released in 2016 and included major revisions, especially of stage III. The purpose of this study was to evaluate the prognostic value of the new AJCC TNM classification in comparison with the 7th edition for stage III gastric cancer.

Methods: Clinical and histopathological data on 1,496 patients operated on for stage III GC according to the seventh edition between 2005 and 2013 were analyzed and compared using 7 th and 8th classifications. The 2 systems were compared in terms of prognostic performance.

Results: The stage shifted for $650(43.45 \%)$ patients: from IIIA to IIIB ( 2 patient, $0.13 \%$ ), from IIIB to IIIA (214 patients, 14.30\%), from IIIB to IIIC ( 99 patients, $6.62 \%$ ), and from IIIC to IIIB ( 335 patients, $22.39 \%$ ). Cox regression multivariate analysis showed both the 8th and 7th TNM classification were independent prognostic factors. The 8th edition system had higher linear trend and likelihood ratio $\mathrm{X}^{2}$ scores, and smaller AIC values compared with those for the 7th edition. However, the performance of the eighth edition did not reveal significant improvement compared to the seventh edition ( $c$-index 0.625 vs. $c$-index $0.616, p=0.085$ ).

Conclusion: The eighth TNM edition may not provide significantly better accuracy in predicting the prognosis of stage III GC. However, to confirm our findings, further studies are warranted.

\section{INTRODUCTION}

The AJCC TNM system is recognized as the most well-established and well-recognized malignant tumor staging system worldwide. Over the past decades, the AJCC TNM staging system has been revised continuously, and the most recent eighth edition of the TNM classification published in 2016 replaced the seventh edition from 2009 [1]. Changes to the latest classification of gastric cancer are mainly based on data analyses from the US and Japan.

The seventh edition N3 stage was divided into N3a (7-15 positive regional lymph nodes) and N3b ( $>15$ positive regional lymph nodes). However, in the 7th edition, the $\mathrm{N} 3$ sub-classification ( $\mathrm{N} 3 \mathrm{a}$ and $\mathrm{N} 3 \mathrm{~b}$ ) do not differ with regards to the final pathologic stage [2]. Recently, the AJCC published the eighth edition of the TNM classification, and several changes to the 8th 
edition of the AJCC staging system for gastric cancer have been proposed (Supplementary Table 1) [1]. A key change adopted in new eighth edition details pN3 as $\mathrm{pN} 3 \mathrm{a}$ and $\mathrm{pN} 3 \mathrm{~b}$ in the final pathologic stage. Thus, a comparison of stage distributions between old and new TNM classifications shows that stages I and II did not change except for T1N3bM0 (changing from IIB in the 7 th ed. to IIIB in the 8 th ed.). The main modification involved a major change to stage III. T2N3bM0 tumors were upstaged from stage IIIA to IIIB, and T3N3bM0 tumors were upstaged from IIIB to IIIC. In addition, T4bN0M0 and T4aN2M0 tumors were downstaged from IIIB to IIIA. Finally, T4aN3aM0 and T4bN2M0 tumors were downstaged from IIIC to IIIB (Figure 1). As stated above, the most important change made to the 8 th edition concerns stage III of gastric cancer. Therefore, in the present study, we mainly evaluated classification changes made in regards to stage III gastric cancer.

To our knowledge, this is the first study to examine GC of the 8th TNM system. The objective of the present study was to evaluate the validity of the proposed 8th edition AJCC system and to identify the optimal TNM classification for stage III gastric cancer based on the prospectively collected database from a large specialized eastern center.

\section{RESULTS}

\section{Patients characteristics}

Data on 1,496 consecutive patients were analyzed. In total, $1,101(73.6 \%)$ of the patients were male and $395(26.4 \%)$ were female with a median age of 62 years (range, 16-101 years). The mean number of dissected LNs was 34.5 (range 5-108). The patient and histopathological characteristics are shown in Table 1.

\section{Seventh and eighth editions of the AJCC TNM classification}

Classifying according to the 2 editions revealed that 961 patients with N3 tumors were divided into 561 patients with $\mathrm{N} 3 \mathrm{a}(58.4 \%)$ and 400 patients with $\mathrm{N} 3 \mathrm{~b}$ (41.6\%). The AJCC stage distributions according to the seventh and eighth editions of the TNM classification are shown in Figure 1. 7th IIIA stage differentiate into 8th IIIA stage and 8th IIIB stage; 7th IIIB stage differentiate into 8th IIIA stage, 8th IIIB stage and 8th IIIC stage; 7th IIIC stage differentiate into 8th IIIB stage and 8th IIIC stage. Our comparison of the 2 classifications revealed that AJCC III stage tumors changed in 650 (43.45\%), which

\begin{tabular}{|c|c|c|c|c|c|}
\hline \multicolumn{3}{|c|}{$7^{\text {th }} \mathrm{AJCC}$} & \multicolumn{3}{|l|}{$8^{\text {th }} \mathrm{AJCC}$} \\
\hline Stage & Subgroup & $\mathrm{n}$ & Subgroup & $\mathrm{n}$ & Stage \\
\hline \multirow[t]{5}{*}{ IIIA } & T4aN1M0 & 117 & T4aN1M0 & 117 & IIIA \\
\hline & T3N2M0 & 181 & T3N2M0 & 181 & \\
\hline & $\mathrm{T} 2 \mathrm{~N} 3 \mathrm{M} 0$ & 30 & $\mathrm{~T} 2 \mathrm{~N} 3 \mathrm{aM} 0$ & 28 & \\
\hline & & & T4aN2M0 & 204 & \\
\hline & & & T4bN0M0 & 10 & \\
\hline \multirow[t]{5}{*}{ IIIB } & T4bN0M0 & 10 & $\mathrm{~T} 2 \mathrm{~N} 3 \mathrm{bM} 0$ & 2 & IIIB \\
\hline & $\mathrm{T} 4 \mathrm{bN} 1 \mathrm{M} 0$ & 10 & T4bN1M0 & 10 & \\
\hline & T4aN2M0 & 204 & T4bN2M0 & 13 & \\
\hline & T3N3M0 & 272 & T4aN3aM0 & 322 & \\
\hline & & & T3N3aM0 & 173 & \\
\hline \multirow[t]{3}{*}{ IIIC } & T4aN3M0 & 590 & T3N3bM0 & 99 & IIIC \\
\hline & $\mathrm{T} 4 \mathrm{bN} 2 \mathrm{M} 0$ & 13 & T4aN3bM0 & 268 & \\
\hline & $\mathrm{T} 4 \mathrm{bN} 3 \mathrm{M} 0$ & 69 & $\mathrm{~T} 4 \mathrm{bN} 3 \mathrm{a} / \mathrm{bM} 0$ & 69 & \\
\hline
\end{tabular}

Figure 1: AJCC stage and TNM subgroup distributions of the patients according to the seventh and eighth editions of the TNM classification. 
Table 1: Univariate analysis of clinicopathologic factors for 5-year survival rate

\begin{tabular}{|c|c|c|c|}
\hline Factor & Number & 5-year survival rate $(\%)$ & $P$ value \\
\hline Age & & & $<0.001$ \\
\hline$<65$ & 896 & 37.3 & \\
\hline$\geq 65$ & 600 & 27.0 & \\
\hline Gender & & & 0.484 \\
\hline Male & 1101 & 34.6 & \\
\hline Female & 395 & 28.8 & \\
\hline Tumor location & & & 0.028 \\
\hline Upper & 524 & 30.2 & \\
\hline Middle & 384 & 32.0 & \\
\hline Lower & 588 & 36.5 & \\
\hline Tumor size $(\mathrm{cm})$ & & & $<0.001$ \\
\hline$<5.0$ & 399 & 53.2 & \\
\hline$\geq 5.0$ & 1097 & 26.8 & \\
\hline Histological type, $n(\%)$ & & & 0.181 \\
\hline Differentiated & 557 & 36.7 & \\
\hline Undifferentiated & 939 & 33.9 & \\
\hline N stage ( $7^{\text {th }}$ AJCC) & & & $<0.001$ \\
\hline N0 & 10 & 51.4 & \\
\hline N1 & 127 & 53.8 & \\
\hline $\mathrm{N} 2$ & 398 & 46.1 & \\
\hline N3 & 961 & 27.4 & \\
\hline $\mathrm{N}$ stage ( $8^{\text {th }}$ AJCC) & & & $<0.001$ \\
\hline N0 & 10 & 51.4 & \\
\hline N1 & 127 & 53.8 & \\
\hline $\mathrm{N} 2$ & 398 & 46.1 & \\
\hline $\mathrm{N} 3 \mathrm{a}$ & 561 & 30.5 & \\
\hline $\mathrm{N} 3 \mathrm{~b}$ & 400 & 15.4 & \\
\hline TNM stage ( $7^{\text {th }}$ AJCC $)$ & & & $<0.001$ \\
\hline IIIA & 331 & 53.9 & \\
\hline IIIB & 493 & 38.1 & \\
\hline IIIC & 672 & 19.8 & \\
\hline TNM stage ( $8^{\text {th }}$ AJCC) & & & $<0.001$ \\
\hline IIIA & 550 & 49.2 & \\
\hline IIIB & 529 & 30.0 & \\
\hline IIIC & 417 & 15.4 & \\
\hline
\end{tabular}


was defined as the staging shift; $846(56.55 \%)$ patients were not changed in the 8 th edition, which was defined as the staging stable. In detail, patients were reclassified from AJCC stage IIIA to IIIB (2 patient, $0.13 \%$ ), from IIIB to IIIA (214 patients, $14.30 \%$ ), from IIIB to IIIC (99 patients, $6.62 \%$ ), and from IIIC to IIIB (335 patients, $22.39 \%$ ).

\section{Survival differences between the staging shift and staging stable patients}

Figure 2a-2c presents the overall survival curves of the patients according to the classification in the 7th and 8th edition of the AJCC staging system. IIIA stage did not show statistical differences because too few patients changed to new stage in the 8 th edition (Figure $2 \mathrm{a}, \mathrm{p}=0.380$ ). However, the survival curves for staging shift patients versus staging stable patients of stage IIIB/IIIC subgroups according to the classification in the 7 th edition AJCC system were significantly different (Figure $2 b-2 c, p<0.05$ ). Significant differences between survival curves of the staging shift and staging stable patients were also observed in 8th AJCC classifications (Figure 3a-3c, $\mathrm{p}<0.05$ ).

\section{Univariate and multivariate survival analysis}

In univariate analysis, age, tumor size, tumor location, N stage (7th AJCC), N stage (8th AJCC), TNM stage ( 7 th AJCC), and TNM stage (8th AJCC) were significantly correlated with patients' 5-year OS (Table 1). We thus performed multivariate Cox proportional hazard model analysis for factors that had significant correlation with OS. The result showed that the N stage (7th AJCC), $\mathrm{N}$ stage (8th AJCC), TNM stage (7th AJCC), and TNM stage (8th AJCC) were the independent prognostic factors. (Table 2). Figure 4 shows the patient stage-specific survival curves according to the 7 th and 8 th classifications.

\section{Comparisons between the two prognostic classification systems}

The performance of the 7th and 8th edition staging system assessed by the $\mathrm{C}$-index, AIC, likelihood ratio $\chi^{2}$ score, and linear trend $\chi^{2}$ score is presented in Table 3. A statistical assessment of the prognostic performance of the 2 AJCC classification editions based on the c-index reveals a value of $0.616(95 \% \mathrm{CI}, 0.597-0.635)$ for the 7 th edition and a value of 0.625 (95\%CI, 0.604-0.642) for the 8 th edition, however, the difference was not statistically significant $(\mathrm{p}=0.085)$.

\section{DISCUSSION}

Gastric cancer (GC) is the second leading cause of cancer-related death, with the highest mortality rates found in East Asia, including Japan, Korea, and
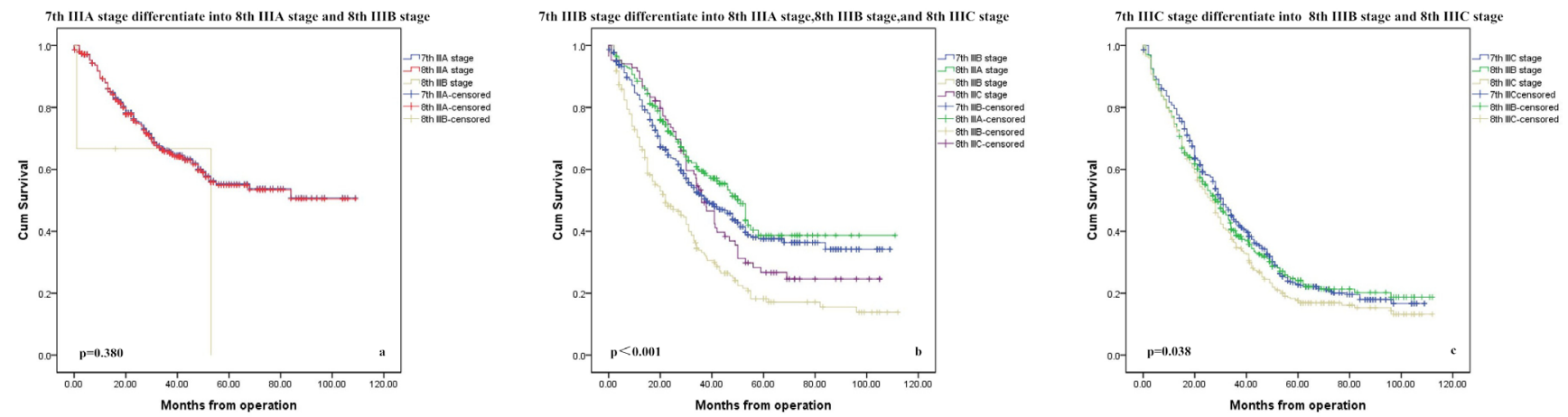

Figure 2: Survival curves by subgroups according to different subgroup of 7 th AJCC classification.
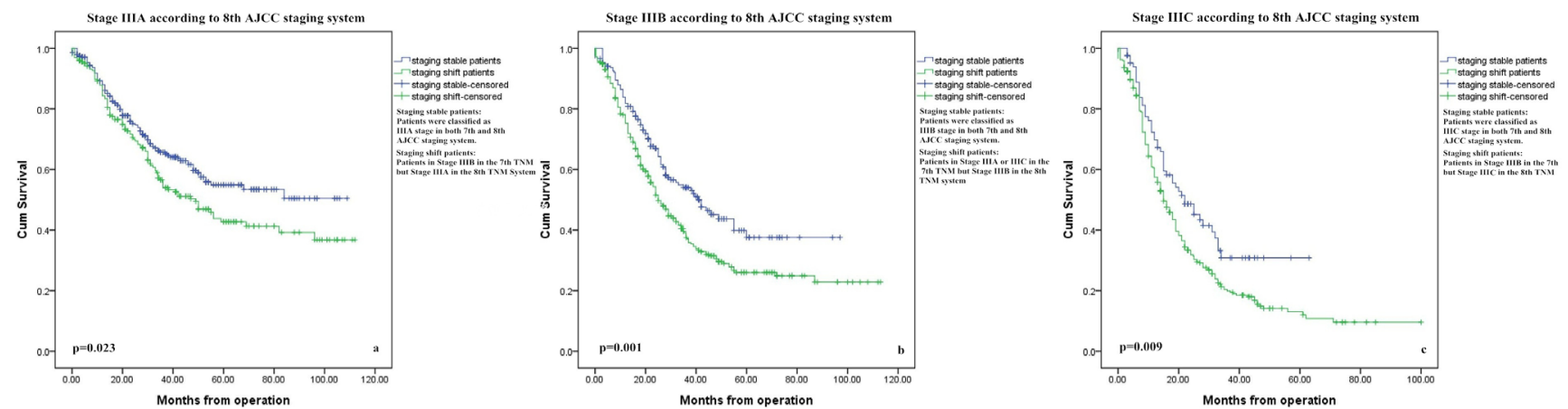

Figure 3: Survival curves for patients with stage III gastric cancer according to their subgroups. 
Table 2: Multivariate analysis with Cox proportional hazard model for prognostic factors

\begin{tabular}{lccc}
\hline Factor & Hazard ratio (HR) & $\mathbf{9 5 \%}$ CI & P value \\
\hline 7th N stage (AJCC) & 1.224 & $0.482-0.867$ & 0.005 \\
8th N stage (AJCC) & 1.657 & $1.218-2.255$ & 0.004 \\
7th TNM stage (AJCC) & 1.469 & $1.260-1.714$ & $<0.001$ \\
8th TNM stage (AJCC) & 1.735 & $1.271-2.367$ & $<0.001$ \\
\hline
\end{tabular}

China [3]. Surgical resection remains the main form of treatment. However, despite advances made in treatment strategies over past decades, the prognosis for stage III gastric cancer is still poor. In China, where gastric cancer is endemic, the majority of patients are diagnosed at middle or late stages, reflecting poor overall survival rates [4]. Therefore, we finally focused on stage III, which represents approximately $50 \%$ of all entire gastric cancer cases diagnosed in China.

Several important changes were made to the recently modified 8th edition of the TNM staging system of gastric cancers released in 2016 from the 7 th edition.
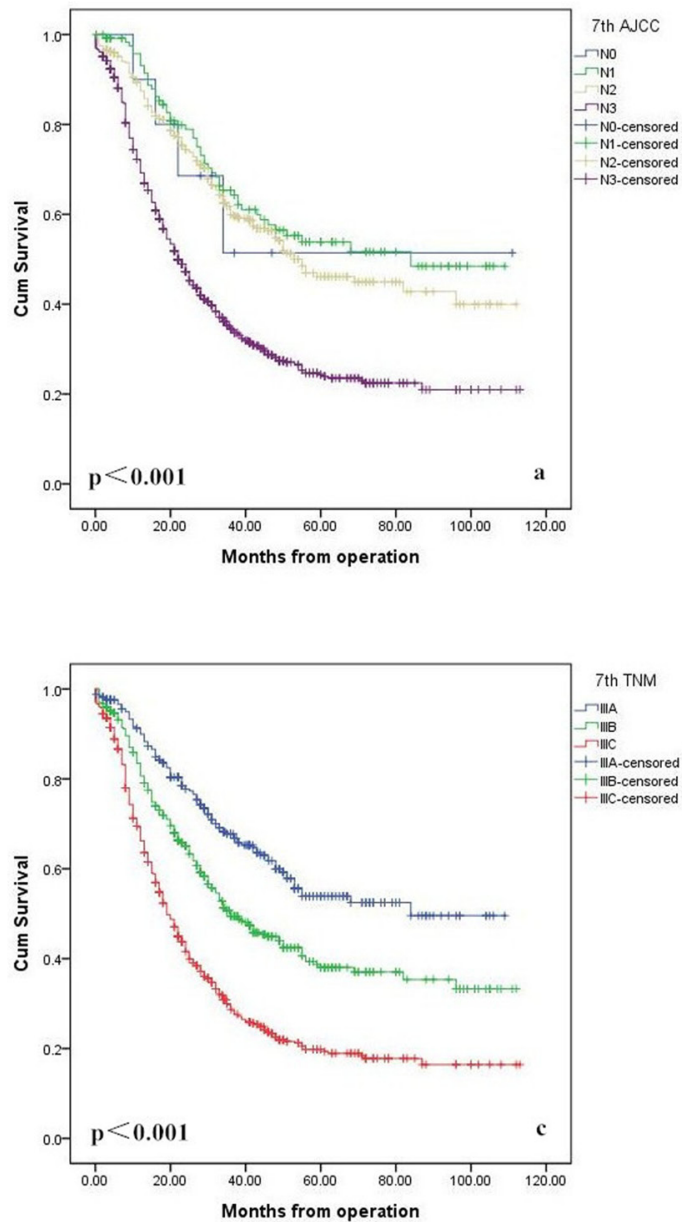

Changes made to the TNM classification and AJCC tumor stages were based on survival analyses performed for gastric cancer listed the NCDB (U.S.) and Shizuoka Cancer Center (Japan) dataset. The eighth edition of the TNM classification system includes substantial changes for gastric cancer, providing more comprehensive tools (cTNM, ypTNM, and pTNM) for the stage grouping of gastric cancer patients under different circumstances that may influence treatments and that may serve as the basis of future clinical studies [5]. In this paper, we mainly discuss changes made to the pTNM classification. The introduction of several new subgroups and sub-stages
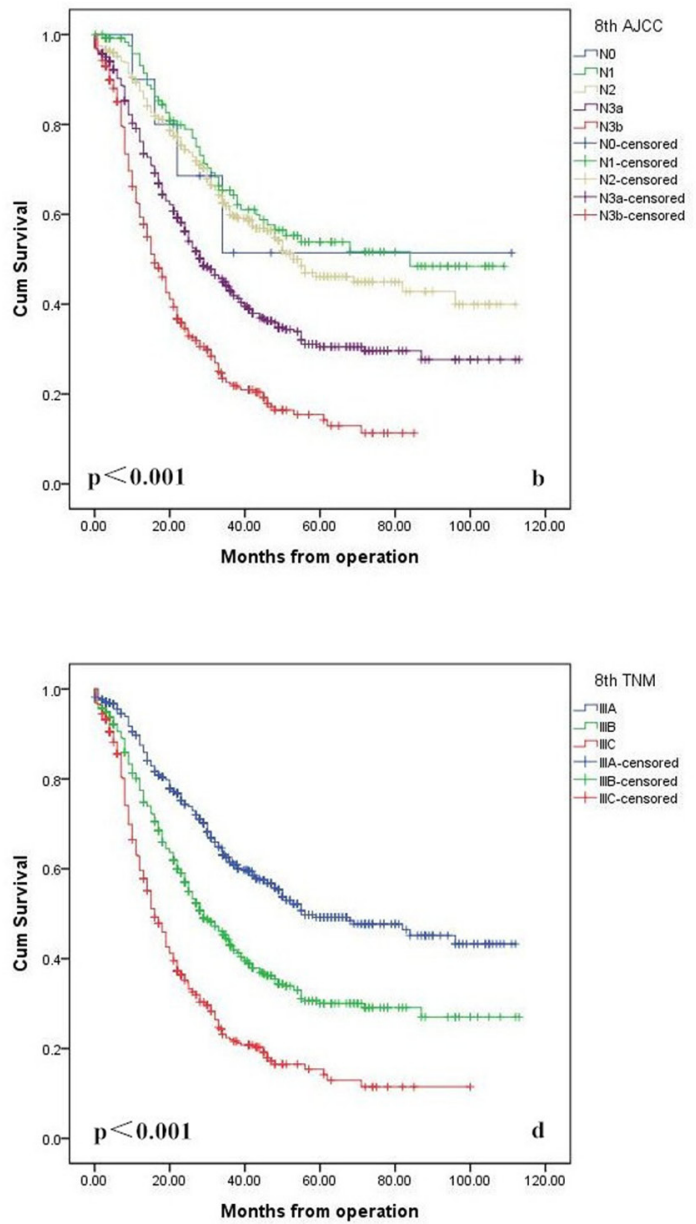

Figure 4: Comparison of survival curves according to $\mathrm{N}$ stage between the 7th (a) and 8th edition (b), and TNM classifications between the 7 th (c) and 8th edition (d). 
Table 3: Comparison of the performance of the $7^{\text {th }}$ and the $8^{\text {th }}$ edition AJCC TNM staging system

\begin{tabular}{|c|c|c|c|c|c|}
\hline & \multicolumn{2}{|c|}{ Concordance indices } & \multirow{2}{*}{ AIC } & \multirow{2}{*}{ Likelihood ratio $\chi^{2}$} & \multirow{2}{*}{ Linear trend $\chi^{2}$} \\
\hline & C-index & Bootstrap 95\% CI & & & \\
\hline $7^{\text {th }}$ AJCC system & 0.616 & 0.597 to 0.635 & 1568.91 & 6861.243 & 5817.383 \\
\hline $8^{\text {th }}$ AJCC system & 0.625 & 0.604 to 0.642 & 1559.39 & 6935.005 & 5882.391 \\
\hline
\end{tabular}

resulted in the creation of a complex and confusing classification for daily clinical use (Figure 1 and Supplementary Table 1).

Concerning the $\mathrm{N}$ category in the 8th edition, the main change made to this category involved splitting N3 staging into N3a (7-15 positive LNs) and N3b (more than 15 LNs nodes). Although the seventh edition N3 classification was sub-classified as N3a and N3b, each subgroup was not an individual determinant of the final TNM stage, which may cause serious problems in underestimating GC severity levels. There is now enough proof of the limitations of the 7th AJCC N3 classification, and the need for $\mathrm{N}$ classification modifications was raised by various investigators prior to the introduction of the 8th edition AJCC TNM classification [6-10]. Therefore, the 8th edition of the TNM classification adopted numeric classifications for N3 classification, and it was divided into 2 subgroups in the final TNM stage. The involvement of $\geq 16$ lymph nodes (N3b) was associated with worse outcomes than cases involving 7-15 positive nodes (N3a) according to a series from Italy [8], and similar results were also found through 2 large Korean studies [10-11]. Our data also confirm that N3a and N3b may represent diseases of differing severity, and the 5-year survival rate of patients according to the eighth edition $\mathrm{N} 3$ a classification is also significantly better than that of patients with N3b stage tumors. Therefore, it appears reasonable to revise the seventh edition $\mathrm{pN} 3(\mathrm{a} / \mathrm{b})$ to $\mathrm{a}$ different $\mathrm{pN}$ classification even if an analysis of $\mathrm{T} 1 \mathrm{~N} 3 \mathrm{~b}$ and $\mathrm{T} 2 \mathrm{~N} 3 \mathrm{~b}$ categories was not possible due to an insufficient number of patients.

Next, we compared the IIIA, IIIB, and IIIC tumor staging guidelines of both editions. T4aN2 and $\mathrm{T} 4 \mathrm{bN} 0$ are now classified as stage IIIA, and T4bN2 is now classified as stage IIIB. In our series, partial cases of stage IIIB (T4aN2 and T4bN0) and IIIC (T4bN2) diseases in the 7th edition system were downstaged to IIIA and IIIB in the 8th edition AJCC. Overall, down-staging was observed in $36.7 \%$ of stage III cases, whereas $6.8 \%$ of stage III cases were up-staged. However, when Marrelli et al. [8] compared the 7 th system with the 6th edition, they found down-staging in $10.4 \%$ of cases and up-staging in $27.2 \%$ cases.

Staging is a key facet of cancer treatment. The accurate staging of cancer patients reveals the progression of a disease, the risk of recurrence and overall survival determinations, which have a significant influence on treatment decisions and which allow one to draw comparisons between patient cohorts across institutions and countries. Recently, International Gastric Cancer Association (IGCA), which is an academic group having nearly 1500 members from 57 countries, proposed a new stage grouping based on a large, worldwide data collection. They established a new evidence-based classification with better stratification than $7^{\text {th }}$ AJCC [12]. Wang et al [11] found that the 7th edition TNM system performs better than the 6th edition in several aspects. A study by Warneke et al [13] concluded that the 7th AJCC classification has become more complex without improving predictability for overall survival in a Western population. Therefore, the authors believed that a simplification of the staging systems for gastric cancer seems justified. Another eastern study found that some subgroups of the seventh edition TNM classification did not demonstrate significantly different survival rates [14]. The 8th edition of the TNM classification attempts to show significant differences in stage III disease survival rates by using a more ideal structure relative to that of the 7 th edition staging system. According to our survival analysis, the 8th TNM edition is more accurate in predicting stage III gastric cancer patients' prognoses than the 7 th edition. However, similar as reported in other malignancy $[15,16]$, it is worth noting that the c-index in this research is less than 0.75 , and potentially because stage III GC includes an extremely heterogeneous group of diseases, thus potentially prohibiting the creation of any meaningful stage grouping based solely on local tumor growth and nodal spread patterns. Other variables will show to significantly influence patient survival rates such as histological and molecule phenotypes. Progress will be achieved by combining the TNM classification system with molecular tools [17].

This study presents several limitations. First, this study was retrospective despite being performed based on a prospectively collected database. It was performed based on data from specialized centers with standardized lymphadenectomy and node retrieval capabilities, and this must be considered when comparing results with other cases. Second, we did not analyze the effects of postoperative chemotherapy procedures on prognoses. Third, the validation of this proposed classification system in another cohort, particularly in a Western population, should be performed. Fourth, the median follow-up period used was only 53 months, which maybe not be a long 
enough period to support definite conclusions. To address these limitations, our results should be validated for different series based on large sample sizes and sufficient follow-up periods.

\section{CONCLUSIONS}

In summary, we first validate the superior prognostic and discriminating value of the 8 th edition AJCC classification for stage III gastric cancer patients. However, novel prognostic biomarkers are urgently needed. We believe that progression of precise stratification tools for the prediction of patient prognoses will be achieved by combining the TNM subgroup classification system with molecular tools, in the near future.

\section{MATERIALS AND METHODS}

\section{Patients}

This study was designed as a retrospective analysis based on prospectively collected data. Between 2005 and 2013, 1,496 patients underwent curative resection with D2 lymphadenectomy for stage III gastric cancer according the seventh edition of the AJCC TNM classification [2] at the Department of Surgery of Fujian Medical University Union Hospital (Table 1). The surgical strategy was according to the Japanese Gastric Cancer Treatment Guidelines. The data on these patients included information on demographic parameters, histopathologic tumor characteristics, and survival rates. We excluded the following patients from the study: (1) patients with pathological I or II stage conditions, (2) patients undergoing palliative surgery, (3) patients with distant metastasis, and (4) patients with synchronous malignancies. (5) We excluded patients who had undergone neoadjuvant chemotherapy because in the 8th edition AJCC cancer staging manual, a special postneoadjuvant therapy stage (ypTNM) grouping system had been provided based on United States National Cancer Data Base (NCDB). The flowchart of the patient selection process was shown in Supplementary Figure 1. The 8th TNM classification's application was simulated in these cases and was compared on a case-by-case basis with the 7 th edition of TNM staging.

All operations were performed by experienced surgeons who had experience of more than 300 cases of gastrectomy before study start [18]. Adjuvant chemotherapy with 5-fluorouracil (5-FU)-based regimens (mostly 5-FU with cisplatin) was recommended to the eligible patients. Postoperatively, patients were examined during follow-up visits every 3 months for the first 2 years and every 6 months thereafter. At each follow-up control, carcinoembryonic antigen and carbohydrate antigen 19-9 levels were measured. Thoracicoabdominal and pelvic computed tomographic scanning or abdominal ultrasonography was performed alternately every 3-6 months. Gastroscopy was performed yearly. 1,349 patients $(90.2 \%)$ were followed up with, and the median follow-up was 53 months (range 2-115).

This study was approved by the Institutional Review Board of the Ethical Committee of Fujian Medical University Union Hospital.

\section{Definitions of the eighth edition TNM classification}

For the eighth edition pTNM classification, definitions of $\mathrm{T}$ and $\mathrm{N}$ classifications were not changed, and only the final staging assignment of the pN3 classification was changed. The seventh edition $\mathrm{pN} 3$ classification was divided into $\mathrm{pN} 3 \mathrm{a}$ and $\mathrm{pN} 3 \mathrm{~b}$ classifications in the eighth edition, and the seventh edition pT4aN2 and T4bN0 classifications were reclassified as stage IIIA in the eighth edition [1]. Supplementary Table 1 shows detailed classifications based on the seventh and eighth editions of the AJCC TNM classification.

\section{Statistical analysis}

All data were analyzed by statistical analysis program package (SPSS 17.0, SPSS Inc., Chicago, IL, USA), and the statistical software "R" (version 2.11.1, the R Foundation for statistical computing). Survival time was calculated from the day of surgical resection, and the day of death or last follow-up was considered as endpoint. Overall survival (OS) was calculated using the Kaplan-Meier method, and the logrank test was employed to determine the significance. The likelihood ratio $\chi^{2}$ test related to the Cox regression model was used to measure homogeneity. The discriminatory ability and monotonicity of gradient assessments were measured with the linear trend $\chi^{2}$ test. To assess potential bias in comparing prognostic systems with different numbers of stages, the Akaike information criterion (AIC) within the Cox proportional-hazard regression model was used. [19]. The predictive accuracy of the model was also evaluated by the concordance index (C-index) [20], which can range from perfect concordance (1.0) to perfect discordance (0.0), the corresponding confidence interval (CI) were obtained by bootstrapping, as previously described [16]. p values for the $\mathrm{C}$-index were computed by assuming asymptotic normality [15]. All statistical tests were performed 2-sided, and a $\mathrm{p}<0.05$ was considered as statistically significant.

\section{ACKNOWLEDGMENTS}

This study was supported by grants Scientific and technological innovation joint capital projects of Fujian Province (2016Y9031), and National Key Clinical Specialty Discipline Construction Program of China (No. [2012]649), and Youth scientific research subject of Fujian provincial health and family planning commission (No. 2015-1-37). 


\section{CONFLICTS OF INTEREST}

All of the authors declare that they have no potential commercial conflicts of interest relevant to this article.

\section{REFERENCES}

1. Ajani JA, In H, Sano T, et al. Stomach. In: Amin MB, editor. AJCC Cancer Staging Manual. 8th ed. New York: Springer-Verlag; 2016.

2. Edge SB, Byrd DR, Compton CC, et al. AJCC Cancer Staging Handbook. 7th ed. New York (NY): SpringerVerlag; 2010.

3. Sasako M, Sakuramoto S, Katai H, Kinoshita T, Furukawa H, Yamaguchi T, Nashimoto A, Fujii M, Nakajima T, Ohashi Y. Five-year outcomes of a randomized phase III trial comparing adjuvant chemotherapy with S-1 versus surgery alone in stage II or III gastric cancer. J Clin Oncol. 2011; 29:4387-93.

4. Wang DS, Ren C, Qiu MZ, Luo HY, Wang ZQ, Zhang DS, Wang FH, Li YH, Xu RH. Comparison of the prognostic value of various preoperative inflammation-based factors in patients with stage III gastric cancer. Tumour Biol. 2012; 33:749-56.

5. Warneke VS, Behrens HM, Hartmann JT, Held H, Becker T, Schwarz NT, Röcken C. Cohort Study Based on the Seventh Edition of the TNM Classification for Gastric Cancer: Proposal of a New Staging System. J Clin Oncol. 2011; 29:2364-71.

6. Saito H, Fukumoto Y, Osaki T, Fukuda K, Tatebe S, Tsujitani S, Ikeguchi M. Prognostic significance of level and number of lymph node metastases in patients with gastric cancer. Ann Surg Oncol. 2007; 14:1688-93.

7. Marrelli D, Morgagni P, de Manzoni G, Coniglio A, Marchet A, Saragoni L, Tiberio G, Roviello F, and Italian Research Group for Gastric Cancer (IRGGC). Prognostic value of the 7th AJCC/UICC TNM classification of noncardia gastric cancer: analysis of a large series from specialized Western centers. Ann Surg. 2012; 255:486-91.

8. Karpeh MS, Leon L, Klimstra D, Brennan MF. Lymph node staging in gastric cancer: is location more important than Number? An analysis of 1,038 patients. Ann Surg. 2000; 232:362-71

9. Ahn HS, Lee HJ, Hahn S, Kim WH, Lee KU, Sano T, Edge SB, Yang HK. Evaluation of the seventh American Joint Committee on Cancer/International Union Against Cancer Classification of gastric adenocarcinoma in comparison with the sixth classification. Cancer. 2010; 116:5592-98.

10. Jung H, Lee HH, Song KY, Jeon HM, Park CH. Validation of the seventh edition of the american joint committee on cancer TNM staging system for gastric cancer. Cancer. 2011; 117:2371-2378.

11. Wang W, Sun XW, Li CF, Lv L, Li YF, Chen YB, Xu DZ, Kesari R, Huang CY, Li W, Zhan YQ, Zhou ZW. Comparison of the 6th and 7th editions of the UICC TNM staging system for gastric cancer: results of a Chinese single-institution study of 1,503 patients. Ann Surg Oncol. 2011; 18:1060-67.

12. Sano T, Coit DG, Kim HH, Roviello F, Kassab P, Wittekind C, Yamamoto Y, Ohashi Y. Proposal of a new stage grouping of gastric cancer for TNM classification: International Gastric Cancer Association staging project. Gastric Cancer. 2017; 20:217-25.

13. Reim D, Loos M, Vogl F, Novotny A, Schuster T, Langer R, Becker K, Höfler H, Siveke J, Bassermann F, Friess H, Schuhmacher C. Prognostic Implications of the Seventh Edition of the International Union Against Cancer Classification for Patients With Gastric Cancer: The Western Experience of Patients Treated in a Single-Center European Institution. J Clin Oncol. 2013; 31:263-71.

14. Zhang J, Niu Z, Zhou Y, Cao S. A Comparison Between the Seventh and Sixth Editions of the American Joint Committee on Cancer/International Union Against Classification of Gastric Cancer. Ann Surg. 2013; 257:81-86.

15. Spolverato G, Bagante F, Weiss M, Alexandrescu S, Marques HP, Aldrighetti L, Maithel SK, Pulitano C, Bauer TW, Shen F, Poultsides GA, Soubrane O, Martel G, et al. Comparative performances of the 7 th and the 8 th editions of the American Joint Committee on Cancer staging systems for intrahepatic cholangiocarcinoma. J Surg Oncol. 2017 Feb 14. https://doi.org/10.1002/jso.24569. [Epub ahead of print].

16. Zivanovic O, Leitao MM, Iasonos A, Jacks LM, Zhou Q, Abu-Rustum NR, Soslow RA, Juretzka MM, Chi DS, Barakat RR, Brennan MF, Hensley ML. Stage-specific outcomes of patients with uterine leiomyosarcoma: a comparison of the international Federation of gynecology and obstetrics and american joint committee on cancer staging systems. J Clin Oncol. 2009; 27:2066-72.

17. Salazar R, Roepman P, Capella G, Moreno V, Simon I, Dreezen C, Lopez-Doriga A, Santos C, Marijnen C, Westerga J, Bruin S, Kerr D, Kuppen P, et al. Gene expression signature to improve prognosis prediction of stage II and III colorectal cancer. J Clin Oncol. 2011; 29:17-24.

18. Yoshikawa T, Cho H, Rino Y, Yamamoto Y, Kimura M, Fukunaga T, Hasegawa S, Yamada T, Aoyama T, Tsuburaya A. A prospective feasibility and safety study of laparoscopyassisted distal gastrectomy for clinical stage I gastric cancer initiated by surgeons with much experience of open gastrectomy and laparoscopic surgery. Gastric Cancer. 2013; 16:126-32.

19. Yoon HM, Ryu KW, Nam BH, Cho SJ, Park SR, Lee JY, Lee JH, Kook MC, Choi IJ, Kim YW. Is the new seventh AJCC/UICC staging system appropriate for patients with gastric cancer? J Am Coll Surg. 2012; 214:88-96.

20. Harrell FE Jr, Lee KL, Mark DB. Multivariable prognostic models: issues in developing models, evaluating assumptions and adequacy, and measuring and reducing errors. Stat Med. 1996; 15:361-87. 